\title{
Germicidal Activities of Some Selected Disinfectants on Staphylococcus aureus and Escherichia Coli
}

\section{Celestina MI*}

Department of Biotechnology, Federal Uiversity of Technology, Nigeria

*Corresponding author: Mgbemena Ifeyinwa Celestina, Department of Biotechnology, Federal Uiversity of Technology, P.M.B. 1526, Owerri, Imo State, Nigeria, Tel: +234 8037947998; Email: drifeyinwac@gmail.com/ifeyinwa.mgbemena@futo.edu.ng

\section{Research Article}

Volume 5 Issue 2

Received Date: March 17, 2020

Published Date: June 16, 2020

DOI: $10.23880 /$ oajmb-16000161

\section{Abstract}

The germicidal efficacy of four common disinfectants used for different purposes was tested against two common pathogens namely Escherichia coli and Staphylococcus aureus. The disinfectants (Dettol, Jik, Izal and Purit) were diluted with sterile distilled water to achieve different concentrations $(100 \%, 50 \%, 25 \%, 12.5 \%$ and $6.25 \%)$ and they were tested on the two organisms using Agar well diffusion method. The plates were allowed to incubate for 24 hours at $37^{\circ} \mathrm{C}$.The germicidal efficiency of the disinfectants was evaluated by measuring the zone of inhibition of each disinfectant based on their varying concentrations. Dettol was observed to have the highest inhibition at $100 \%$ concentration and was more germicidal on E. coli than S. aureus with Minimal Inhibitory Concentration (MIC) value of 1:16 dilution against the two test organisms. This was closely followed by Jik which also showed more inhibitory activity against $E$. coli at the initial concentration recording the second highest inhibition rate compared to other disinfectants, but its efficacy decreased as the concentration dropped. Jik exhibited MIC value of 1:8 and 1:2 dilutions for Staphylococcus aureus and Escherichia coli respectively. Purit showed more inhibitory activity on $S$. aureus with $3.8 \mathrm{~mm}$ zone of inhibition as against $1.3 \mathrm{~mm}$ at $100 \%$ concentration, recording MIC value of 1:8 dilution on $S$. aureus and 1:16 dilution for $E$. coli. The disinfectant Izal was observed to be the lowest as it did not inhibit the growth of any of the organisms, indicating resistance of the organisms to the disinfectant at all concentrations. All the disinfectants apart from Izal inhibited the two test isolates. Only Dettol proved to be best among them. Therefore, Dettol is encouraged to be used in homes to prevent pathogenic infection.

Keywords: Epidermics; Phenolics; Iodophors; Formaldhyde; Glutaraldehyde; Ortho-Phthalaldehyde, Hydrogen Peroxide; Peracetic Acid; Sporostatic

Abbreviations: MIC: Minimal Inhibitory Concentration; UV: Ultraviolet Radiation.

\section{Introduction}

Microorganisms are ubiquitous and constitute a major part of every ecosystem. In any environment or habitat, they could exist freely or as parasites. In some cases, they live as transient contaminants in fomites or hands where they constitute a major health hazard as sources of community and hospital acquired infections [1,2]. The increasing incidence of epidemic outbreaks of certain disease and its rate of spread from one community to the other has become a major public health concern [3] that may lead to epidermics if not contained.

The risk of these infections from pathogenic microorganisms on environmental surfaces derives not only from their presence but also from their ability to survive on many surfaces. For infectious diseases to be contained in a manner that is economically sustainable, contaminated biotic surfaces such as skin, contaminated abiotic surfaces 


\section{Open Access Journal of Microbiology \& Biotechnology}

such as medical devices, and kitchen equipment exposed to cross contamination must be disinfected to prevent pathogens. These contaminated areas are not just the only risk factors for infection but also contaminated places used by the public such as toilets, door handles and contaminated air causing transmission of pathogens from one individual to the other and also contamination of kitchen utensils causing a cross contamination between the kitchen equipment and foods are risk factors for health threatening infections. Also inadequate disinfection of these equipment and air can be a risk factor in the transmission of pathogens such as; Staphylococcus aureus, Escherichia coli, Vibrio cholera, Salmonella typhimurium and Staphylococcus epidermidis. Disinfection is an essential tool to help provide a healthy environment by reducing the pathogen loads, disease transmission and postoperative infection. Disinfection is the destruction of microorganisms, applied on clean surfaces so as to reduce the number of microorganisms to a level that will not lead to harmful contamination of objects in contact with surfaces [4]. Failure to carry out disinfection applications has been the main cause of various disease outbreaks. Generally, disinfectants are substances used in disinfection and they are antimicrobial agents that are applied to the surface of nonliving objects to destroy microorganisms that are living on the objects. Most disease causing pathogens are probably caused by lack of proper disinfection especially in the rural areas of Nigeria, where disinfectants might be out of reach or people staying there are ignorant of its relevance. Disinfectants are used extensively in hospitals and other health care settings for a variety of topical and hard-surface applications. In particular, they are an essential part of infection control practices and aid in the prevention of nosocomial infections [5]. Disinfectants as biocides can be sporostatic but are not necessarily sporicidal [6]. Alcohols, chlorine and chlorine compounds, quaternary ammonium compounds, phenolics, iodophors, formaldehyde, glutaraldehyde, ortho-phthalaldehyde, hydrogen peroxide, peracetic acid are examples of disinfectants used. Microbicide metals, ultraviolet radiation (UV), pasteurization were also used for disinfection of surfaces, as miscellaneous inactivating agents [7].

The choice of the disinfectant to be used depends on a particular situation. Some disinfectants have a wide spectrum, whilst others kill a smaller range of pathogenic organisms, but are preferred for other properties that may be non-corrosive, non-toxic, or inexpensive [8]. The effectiveness of disinfectants is limited and much dependent on application conditions [9]. The factors which control the efficiency of disinfectants are microbial type and growth condition; interfering substances; acidity-pH; temperature; contact time; and concentration [8,9]. This study is aimed at determining the germicidal activities of some disinfectants on Staphylococcus aureus and Escherichia coli.

\section{Materials and Methods}

\section{Sterilization of Materials and Media Preparation}

The glass wares such as pipettes, test tubes etc. were sterilized in an autoclave at $121^{\circ} \mathrm{C}$ for 15 minutes and allowed to cool before use. The culture media made from the hydrated and commercial powdered form was prepared according to the manufacturer's guideline.

\section{Collection of Samples}

Samples of four commonly used household disinfectants namely: Dettol, Jik, Izal and Purit were purchased from Ekeonunwa market located at Douglas road, Owerri, Imo state and taken to the microbiology laboratory for analyses.

\section{Test Isolates}

Pure cultures of Staphylococcus aureus and Escherichia coli gotten from water sources were obtained. The test isolates were sub-cultured in a Nutrient agar. The isolates restored in slant bottles in a fridge for future use.

\section{Serial Dilution of Disinfectants}

A series of decreasing concentration of disinfectants was obtained using two-fold serial dilution method where by $5 \mathrm{mls}$ of sterile distilled water was transferred into 20 test tubes using the micro pipette whereby each disinfectant has 5 test tubes. $5 \mathrm{ml}$ of the concentrated disinfectant was transferred to the first test tube containing $5 \mathrm{mls}$ of distilled water and was mixed thoroughly to give a concentration of $1: 1$. From this tube, $5 \mathrm{ml}$ aliquot was transferred to other test tubes to give a concentration of 1:2, 1:4, 1:8, and 1:16.

\section{Agar Well Diffusion}

Following the media preparation, it was allowed to cool and solidify, and then the agar plate surface was inoculated with strains of Staphylococcus aureus and Escherichia coli using streak plate method by using a swab stick in spreading a volume of the inoculum over the entire agar surface under a sterile working condition to avoid contamination. Then a hole with a diameter of 6 to $8 \mathrm{~mm}$ was aseptically made with a sterile core borer and a volume of the test disinfectant was introduced into the well using a micropipette. 20 plates were used respectively for each test organism. Then, the agar plates were incubated at $37^{\circ} \mathrm{C}$ under suitable condition for 24 hours. The disinfectant sample diffusion in the agar medium and its activity was observed in form of growth on the surface of the inoculum. Also, a clear zone of inhibition was observed around the well diffusion of the disinfectants. The zone of inhibition was measured in millimetres using a transparent 
measurement ruler. This is done by taking the plate to a nonreflective surface and is measured from the centre of the well to the edge of the area with zero growth. This measures the radius of the zone of inhibition and multiplying that by two gives the diameter.

\section{Results}

The germicidal activities of different concentrations of disinfectants against Staphylococcus aureus and Escherichia coli showed that Dettol was the most effective disinfectant against the two test organisms achieving $4.4 \mathrm{~mm}$ and $4.2 \mathrm{~mm}$ zone of inhibition at the initial concentration for each organism respectively. Even though its germicidal efficacy reduced with decreased concentration, it was still actively inhibitory. Its inhibitory activity on the growth of the two isolates was more on Escherichia coli than Staphylococcus aureus. The figure below showed that at the initial concentration, Dettol was the most effective against the test isolates, while Jik had the second highest inhibition against E. coli and Purit had the second highest inhibition against $S$. aureus. Meanwhile, Izal did not inhibit the growth of any of the test isolates even at $100 \%$ concentration.

On S. aureus, Dettol was observed to be the most effective at $100 \%$ concentration and also showed activity in all the concentrations; this was followed by Purit and then Jik. However, as the concentrations decreased, the organism showed lesser sensitivity to the disinfectants, as could be seen from figure below, Dettol showed only $1.8 \mathrm{~mm}$ zone of inhibition at the lowest concentration. Purit inhibited the growth of the organism recording $3.0 \mathrm{~mm}$ zone of inhibition at 1:8 dilution on $S$. aureus. The disinfectant, Jik showed $2.8 \mathrm{~mm}$ at $100 \%$ concentration and its activity slowly deceased until no zone of inhibition was observed at 1:16 dilution $(6.25 \%$ concentration).

On Escherichia coli, the germicidal activities of the disinfectants on the organism showed that Dettol had the highest inhibition with $4.4 \mathrm{~mm}$ zone of inhibition at $100 \%$ concentration. Although its activity dropped drastically as the concentration decreased, it still recorded highest inhibition against the organism even at the lowest concentration. This is followed by Jik but its activity decreased rapidly with no visible growth observed at 25\%, 1.25\% and $6.25 \%$ concentration. The disinfectant Purit was fairly effective against E. coli at various concentrations. Meanwhile, its highest growth inhibition was achieved at $25 \%$ concentration (Figure 1 \& Tables 1,2).

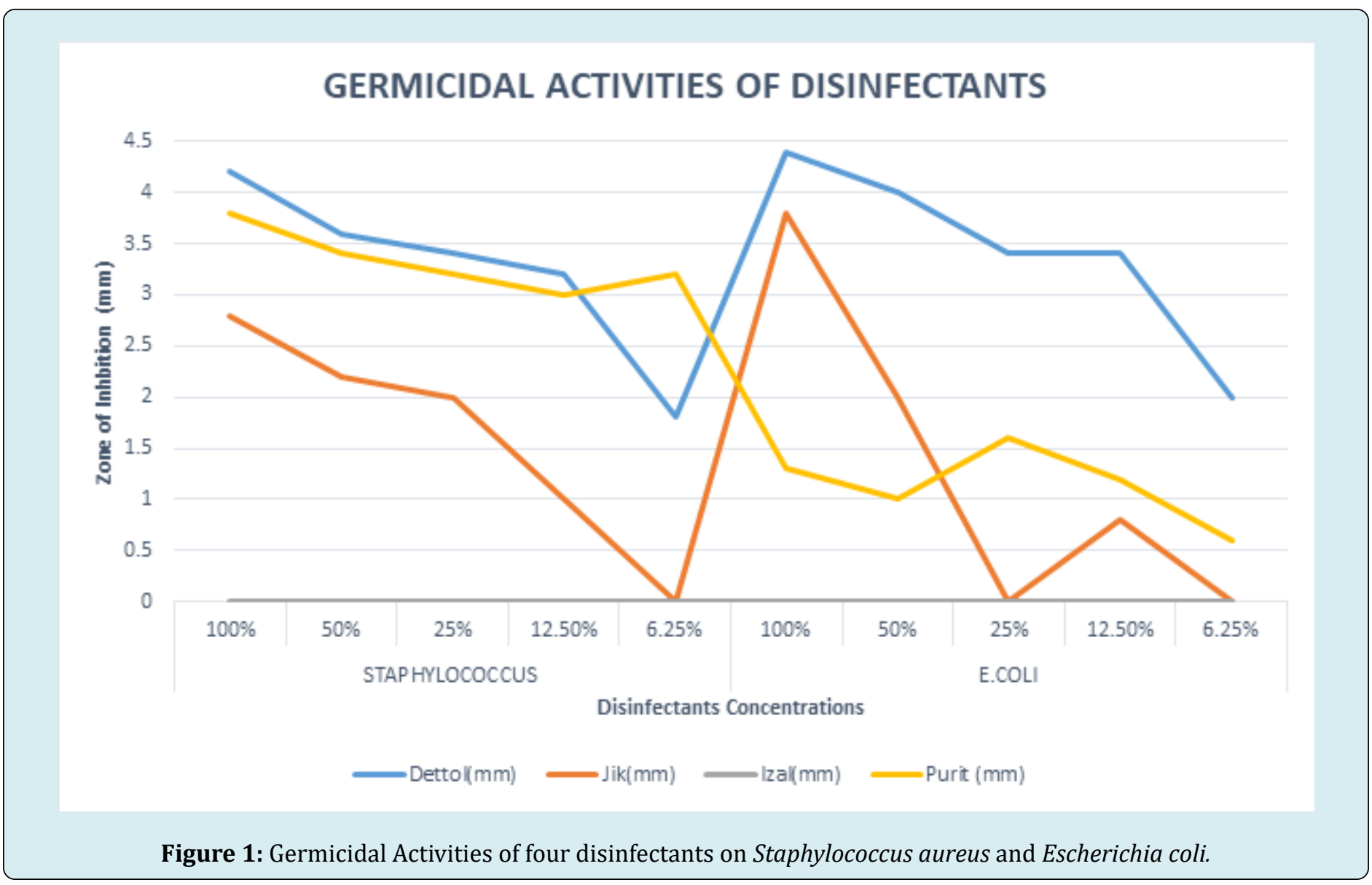




\section{Open Access Journal of Microbiology \& Biotechnology}

\begin{tabular}{|c|c|c|c|c|c|}
\hline Disinfectants & $\mathbf{1 0 0 \%}$ & $\mathbf{5 0 \%}$ & $\mathbf{2 5 \%}$ & $\mathbf{1 2 . 5 0 \%}$ & $\mathbf{6 . 2 5 \%}$ \\
\hline Dettol $(\mathrm{mm})$ & $4.4 \mathrm{~mm}$ & $3.6 \mathrm{~mm}$ & $3.4 \mathrm{~mm}$ & $3.2 \mathrm{~mm}$ & $1.8 \mathrm{~mm}$ \\
\hline Jik $(\mathrm{mm})$ & $2.8 \mathrm{~mm}$ & $2.2 \mathrm{~mm}$ & $2.0 \mathrm{~mm}$ & $1.0 \mathrm{~mm}$ & $0.0 \mathrm{~mm}$ \\
\hline Izal $(\mathrm{mm})$ & $0.0 \mathrm{~mm}$ & $0.0 \mathrm{~mm}$ & $0.0 \mathrm{~mm}$ & $0.0 \mathrm{~mm}$ & $0.0 \mathrm{~mm}$ \\
\hline Purit $(\mathrm{mm})$ & $3.8 \mathrm{~mm}$ & $3.4 \mathrm{~mm}$ & $3.2 \mathrm{~mm}$ & $3.0 \mathrm{~mm}$ & $0.0 \mathrm{~mm}$ \\
\hline
\end{tabular}

Table 1: Data of Zone of Inhibition of S. aureus at different Concentrations of each Disinfectant.

\begin{tabular}{|c|c|c|c|c|c|}
\hline Disinfectants & $\mathbf{1 0 0} \%$ & $\mathbf{5 0 \%}$ & $\mathbf{2 5 \%}$ & $\mathbf{1 2 . 5 0 \%}$ & $\mathbf{6 . . 2 5 \%}$ \\
\hline Dettol $(\mathrm{mm})$ & $4.2 \mathrm{~mm}$ & $4.0 \mathrm{~mm}$ & $3.4 \mathrm{~mm}$ & $3.4 \mathrm{~mm}$ & $2.0 \mathrm{~mm}$ \\
\hline Jik $(\mathrm{mm})$ & $3.8 \mathrm{~mm}$ & $2.0 \mathrm{~mm}$ & $0.0 \mathrm{~mm}$ & $0.0 \mathrm{~mm}$ & $0.0 \mathrm{~mm}$ \\
\hline Izal $(\mathrm{mm})$ & $0.0 \mathrm{~mm}$ & $0.0 \mathrm{~mm}$ & $0.0 \mathrm{~mm}$ & $0.0 \mathrm{~mm}$ & $0.0 \mathrm{~mm}$ \\
\hline Purit $(\mathrm{mm})$ & $3.2 \mathrm{~mm}$ & $1.3 \mathrm{~mm}$ & $1.0 \mathrm{~mm}$ & $0.6 \mathrm{~mm}$ & $0.4 \mathrm{~mm}$ \\
\hline
\end{tabular}

Table 2: Data of Zone of Inhibition of E.coli at Different Concentrations of Each Disinfectant.

\section{Discussion}

Thepotencyofdisinfectantsisveryessentialto developthe germicidal activities toward controlling microbial population and prevention of infection and disease transmission. The germicidal activities of household disinfectants (Dettol, Jik, Izal and Purit) against Staphylococcus aureus and Escherichia coli were analysed in this study. Dettol showed more germicidal activity to Escherichia coli than $S$. aureus. The two isolates were susceptible to this disinfectant till 1:16 dilution where it had the lowest growth inhibition rate. The MIC of Dettol was at 1:16 dilution for both organisms, the values were the highest compared to other test disinfectants. The result also showed that Dettol hah highest activity when tested at $100 \%$ concentration. Although the lesser the concentration, the lesser the inhibition rate but most importantly, it displayed inhibitory activity at various concentrations compared to others. Inhibitory activities of Dettol on Escherichia coli were more compared to its effect on Staphylococcus aureus. Therefore, it is safe to say Dettol is more germicidal on E.coli than S. aureus.

The germicidal activities of Jik recorded against the two test isolates showed that it was more germicidal to Escherichia coli than it was to Staphylococcus aureus. The MIC of Jik disinfectant was 1:16 dilution for the two isolates. However at 1:4, 1:8 and 1:16 dilutions, it was observed that $E$. coli was resistant to this disinfectant. While at 1.16 dilution, $S$. aureus was resistant to Jik implying that $E$. coli is more resistant to the disinfectant than $S$. aureus. It was also recorded that at $100 \%$ concentration, the disinfectant Jik was more germicidal on $S$. aureus. However, it is known that Gram-negative bacteria are more resistant than Grampositive bacteria to agents such as hydrochloric acid, ethyl alcohol and sodium hypochlorite $[10,11]$ suggested that gram negative bacteria were resistant to effects by disinfectant than gram positive bacteria probably due to their having a more complex cell wall. However, this does not corroborate with our findings, in that the Gram negative bacteria (E. coli) did not show much resistance to Dettol, purit and Jik but showed resistance to Izal when compared to the gram positive bacteria (Staphylococcus aureus). This could be attributed to the differences in their active components, the differences in the activity of the disinfectants, as well as the differences in their mode of action or likewise the media components could also have affected the outcome of the activity testing, because the presence of organic matter has been identified as a factor that affects the action of disinfectants [12].

The highest germicidal activities displayed by Dettol were closely followed by Purit. The disinfectant sample was observed to be more effective against Staphylococcus aureus than Escherichia coli with $3.8 \mathrm{~mm}$ zone of inhibition at 1:1 dilution (100\%). Although its efficacy reduced subsequently with decrease in concentration, it was the most efficient disinfectant sample against Staphylococcus aureus at 1:8 dilutions. The MIC for the test isolates was 1.16 dilutions for Escherichia coli and 1:8 dilutions for Staphylococcus aureus. However, against Escherichia coli, the disinfectant Purit was fairly germicidal to it having $3.2 \mathrm{~mm}$ zone of inhibition at $100 \%$ concentration implying that E.coli was more resistant to the disinfectant than S. aureus.

The germicidal activity of the disinfectant Izal as recorded against the test organisms was the lowest when compared to others. It did not inhibit the growth of the test isolates at any dilution after 24 hours of incubation. It was observed to have $0.0 \mathrm{~mm}$ zone of inhibition, indicating that the test organisms are generally resistant to the disinfectant Izal even at $100 \%$ concentration. This implies that Izal had the lowest germicidal activity among the four disinfectant tested and this low performance could be caused by development of 


\section{Open Access Journal of Microbiology \& Biotechnology}

resistant of microbes against this disinfectant over the years, the disinfectant has been a regular household disinfectant in homes, schools, hospitals. However, it is essential for manufacturers of the disinfectant product, Izal, to upgrade the chemical constituents of the disinfectant, thereby increasing its germicidal efficiency in order to increase the competition between present and oncoming disinfectants. Okore CC, et al. [13] reported that Izal did not inhibit S. aureus at zero dilution which actually corroborates with the result obtained in this study where no growth inhibition on the two test organisms was observed for any of the concentrations even at $100 \%$, but they further reported that undiluted Izal had $17 \mathrm{~mm}$ against E.coli but no inhibition at 1:8 dilution.

The germicidal assessment of the four disinfectants at $100 \%$ showed that Dettol was the most effective against the two test isolates, $S$. aureus and E. coli $(4.4 \mathrm{~mm}$ and $4.2 \mathrm{~mm}$ respectively) compared with other disinfectants. However, Purit was second in its growth inhibition of the $S$. aureus at $100 \%$ concentration while Jik was second in inhibition of $E$. coli compared to other disinfectants. Meanwhile, Purit had the highest inhibition of $S$. aureus at 1:16 dilution while it was the third in inhibition of $E$ coli at 1:16 compared to other disinfectants. It is believe that the use of disinfectants is beneficial in preventing infectious disease and thus results in a public health benefit. However, bactericidal effects of these disinfectants were observed to vary against each microorganism and with the efficacy of disinfectants, appropriate disinfectant must be used against each microorganism.

\section{Conclusion}

The test disinfectants in this study confirmed that they are effective against the two commonest pathogens apart from Izal. But their rate of efficiency differs due to their chemical composition and mechanism of action. Dettol was observed to be the most active of all the disinfectants against the two test isolates at various dilutions. Izal showed to be the disinfectant with the least efficacy against the two test organisms. The frequent use of good disinfectant should be encouraged to reduce cases of disease outbreak caused by pathogenic organisms.

\section{References}

1. Sleigh DJ, Timbury MC (1998) Note on Medical Microbiology, $5^{\text {th }}$ [Edn.], Churchill-Livingstone, New
York. pp: 173.

2. Pittet D, Dharan S, Touveneau S, Sauvan V, Perneger TV (1999) Bacterial contamination of the hands of hospital staff during routine patient care. Arc internal Med 159(8): 821-826.

3. Galtelli M, Deschamp C, Rogers J (2006) An assessment of the prevalence of pathogenic microbial contamination in the rotor wing air ambulance. Air Med J 25(2): 81-84.

4. Vidal-Puig A (2002) Nutrient gene interactions in health and disease

5. Rutala WA, Gergen MF, Weber DJ (2006) Efficacy and functional impact of disinfectants. Infect Control Hosp Epidemiol 27(4): 372-377.

6. Johnston MD, Lambert RJ, Hanlon GW, Denyer SP (2002) A rapid method for assessing the suitability of quenching agents for individual biocides as well as combinations. Journal of Applied Microbiology 92(4): 784-789.

7. Kırmusaoglu S (2018) Introductory Chapter: Overview of Disinfection.

8. Chmielewski RAN, Frank JF (2003) Biofilm formation and control in food processing facilities. Comprehensive reviews in food science and food safety 2(1): 22-32.

9. Bessems E (2008) The effect of practical conditions on the efficacy of disinfectants. International Biodeterioration \& Biodegradation 41(3-4): 177-183.

10. Moorman M, Nettleton W, Ryser E, Linz J, Pestka J (2005) Altered sensitivity to a quaternary ammonium sanitizer in stressed Listeria innocua. Journal of Food Production 68(8): 1659-1663.

11. Mamman PH, Kazeem HM, Kwanashie CN (2005) Disinfectant effect of carcil (Alkyl-benxyldimethyl ammonium chloride) on bacteria. Sciences 1: 33-136.

12. Kennedy J, BekJ (1998) Selection and use of Disinfectants. Braska Cooperative extension 40: 5-8.

13. Okore CC, Mbanefo ON, Onyekwere BC, Onyewenjo SC, Ozurumba AU (2014) Antimicrobial Efficacy of Selected Disinfectants. American Journal of Biology and Life Sciences 2(2): 53-57. 